\title{
Flora jurásica de la Mixteca oaxaqueña: patrimonio paleobotánico de México
}

\author{
Diego Enrique Lozano-Carmona y María Patricia Velasco de León
}

\begin{abstract}
Resumen
El Jurásico es uno de los períodos geológicos más emblemáticos y está generalmente asociado con los dinosaurios, sin embargo, la vegetación que dominó el paisaje a nivel mundial estuvo constituida por gimnospermas. En México el primer estudio sobre el registro fósil de plantas del Jurásico fue realizado a principios del siglo xx. Hoy en día se reconocen los afloramientos fosilíferos de la región Mixteca oaxaqueña como de los mejores de México por su abundancia y el buen estado de conservación de los fósiles. Con base en el estudio de éstos, se realizó una nueva propuesta paleoclimática y se actualizó la diversidad paleoflorística de la región. Hay dos localidades que sobresalen: Rosario Nuevo y Río Ñumí. La primera de ellas conserva troncos petrificados con longitudes de hasta ocho metros; mientras que la segunda presenta el listado paleoflorístico más diverso de toda la región. Todos los trabajos paleobotánicos de la Mixteca revisan el trabajo publicado por George Reber Wieland en 1914. Hoy, a más de un siglo de este estudio, podemos destacar y dar a conocer que el patrimonio paleobotánico de la Mixteca oaxaqueña es una fuente de información sobresaliente e irremplazable para la Paleontología mexicana.
\end{abstract}

Palabras clave: gimnospermas, Jurásico, Oaxaca, paleoclima, paleoflora.

\section{Jurassic flora of the Oaxaca Mixteca: Paleobotanical heritage of Mexico}

\begin{abstract}
The Jurassic is one of the most emblematic geological periods, which is generally associated with dinosaurs; however, the landscape was dominated by gymnosperms. The fossil record of Jurassic gymnosperms has been studied since the early 20th century in Mexico, and today the fossiliferous Jurassic outcrops of the Mixteca region are recognized as one of the best in Mexico, both for their abundance and the state of conservation of plant fossils. Based on the study of these plant fossils we have generated a new paleoclimatic proposal and updated the paleofloristic diversity. Generally, two localities of the Mixteca region have greater paleontological quality: Rosario Nuevo and Río Numí, the first of which preserves petrified trunks with lengths of up to eight meters; the second has the most complete paleofloristic species list of the region. All the research made on this region is based on the first paleobotanic study by George Reber Wieland in 1914. Today, more than a century away from this work, we recognize the paleobotanical heritage of the Mixteca, and its exceptional informational role for Mexican Paleontology.
\end{abstract}

Keywords: gymnosperms, Jurassic, Oaxaca, paleoclimate, paleoflora. 
"Flora jurásica de la Mixteca oaxaqueña: patrimonio paleobotánico de México" Diego Enrique Lozano-Carmona y María Patricia Velasco de León Vol. 21, Núm. 3, mayo-junio 2020 Revista Digital Universitaria

\section{Diego Enrique Lozano-Carmona}

coralillo8@gmail.com

Profesor de Asignatura adscrito a la carrera de Biología de la Facultad de Estudios Superiores Zaragoza. Su línea de investigación es sobre gimnospermas mesozoicas. Obtuvo el título de Biólogo en la Facultad de Estudios Superiores Zaragoza y el grado de Maestro en Ciencias Biológicas con Mención Honorífica por el Posgrado en Ciencias Biológicas, ambos de la unam. Ha recibido el premio a la mejor tesis de Licenciatura y Maestría, en 2013 y 2017 respectivamente, ambos reconocimientos otorgados por la Sociedad Mexicana de Paleontología, A. C. (SOMEXPAL), y de la cual es miembro activo desde 2011. Ha participado en proyectos de investigación financiados por PAPIIT-DGAPA-UNAM y CONACYT sobre distribución y paleoecología de las gimnospermas jurásicas del Terreno Mixteco en el sur de México durante el periodo de 2010 al 2012, y del 2016 al 2018 en un proyecto de investigación con tema de diversidad de la flora del Pérmico de México. Desde 2011 ha presentado los resultados de sus investigaciones de tesis en congresos y simposios de paleontología y paleobotánica nacionales e internacionales. Ha publicado artículos científicos en revistas nacionales e internacionales y es participante activo de actividades de divulgación científica con la colección itinerante de Paleontología de la FES Zaragoza. Actualmente es el webmaster del sitio web de la someXPAL.

\section{María Patricia Velasco de León}

pativel@unam.mx

Bióloga egresada de la Facultad de Ciencias, donde realizó sus estudios de maestría y doctorado en el área de sistemática. Actualmente es profesora de Tiempo completo titular C de la Carrera de Biología de la Facultad de Estudios Superiores Zaragoza, UnAm, a partir de 2016. Fundadora y curadora de la Colección de Paleontología de la Carrera de Biología de la Facultad de Estudios Superiores Zaragoza, unAm desde 1983. Su área de interés es el estudio en la sistemática y anatomía de las gimnospermas del Pérmico y Jurásico. También ha realizado investigación en estudios paleoambientales conjuntando procesos de sedimentación, tafonómicos y de distribución de paleofloras. Responsable de proyectos de investigación financiados por el conAcyT y la DGAPA. Autora de artículos científicos, directora de tesis de posgrado, licenciatura y presidente de la someXPAL en el bienio 2015-2017. También ha participado como editora invitada en la revista de la Sociedad Mexicana de Paleontología, revisora de artículos y proyectos de investigación, así como jurado en concursos de oposición. Otra actividad que ha desempeñado es la divulgación de la Paleontología, exhibiendo la colección itinerante de Paleontología de la FES Zaragoza en diferentes preparatorias, delegaciones y poblados del interior de la República y desde 2016 participa con su equipo de trabajo en el Encuentro con la Tierra organizado por el Museo de Geología de la unam. 


\section{Introducción}

El Jurásico abarco desde hace 201.3 millones de años (Ma), hasta hace 145 Ma, con una duración aproximada de 56.3 Ma y es comúnmente asociado a los dinosaurios, sin embargo, es importante reconocer la diversidad de la vegetación en dicho tiempo geológico. Durante el Jurásico la vegetación del planeta estuvo constituida principalmente por gimnospermas (plantas sin flor y semilla desnuda, ver figura 1) de los órdenes: Bennettitales (actualmente extintas), Cycadales y Pinales. En México se conserva un abundante registro de estos grupos (Silva-Pineda, 1984; Diéguez, 2003; Zhou, 2009; Lozano-Carmona y Velasco-de León, 2016).

Una de las regiones con la flora jurásica más abundante, mejor conocida y conservada es la región Mixteca del estado de Oaxaca. En esta región se han encontrado ejemplares fosilizados de hojas, tallos, estructuras reproductoras y troncos petrificados (Ortega-Chavez, et al., 2017; Velasco-de León et al., 2013, ver figuras 2 y 3). Su estudio ha permitido tener mejor conocimiento del clima, del tipo de vegetación y de la distribución de la flora en México durante el Jurásico.

El estudio de la paleoflora de esta región comenzó desde principios del siglo xx y ha estado marcado por lapsos interrumpidos de prospección y análisis (OrtizMartínez et al., 2013; Velasco-de León et al., 2013; Lozano-Carmona et al., 2016). Estas interrupciones se debieron principalmente a la falta de paleobotánicos mexicanos que dieran continuidad a los estudios que realizaron paleontólogos norteamericanos en la primera mitad del siglo xx.

La Mixteca oaxaqueña fue explorada en busca de fósiles de plantas por varios paleobotánicos. George Reber Wieland fue el primero de ellos, entre 1907 y 1909 realizó los trabajos pioneros, publicando una monografía en 1914 por medio del hoy Instituto de Geología de la unam (Wieland, 1914). Posteriormente, fue hasta la década de 1960 que se retomó el estudio de las localidades fosilíferas de la región. Hoy en día se continúa estudiando la Mixteca y realizando hallazgos paleontológicamente significativos (Delevoryas y Gould, 1971; Silva-Pineda, 1984, Lozano-Carmona y Velasco-de León, 2016). Los que se comentan en este artículo son sólo algunos de estos hallazgos. Por lo tanto, el objetivo de esta contribución es brindar un panorama histórico destacando los avances en el conocimiento de la flora del Jurásico de la Mixteca, a más de 100 años de la monografía de G. R. Wieland y comentar la importancia de la vegetación durante este período.

\section{El clima y la floradela Mixteca oaxaqueñad uranteelJurásico}

A finales del siglo xx, con base en décadas de estudio de la paleoflora de la Mixteca, los paleobotánicos llegaron a concluir que la dominancia de Bennettitales y la clara ausencia de Ginkgoales y escasez de coníferas indicaban un clima tropical durante el Jurásico en esta región. Esto influyó a nivel nacional e internacional para considerar a esta paleoflora como ya totalmente estudiada (Person y Delevoryas, 1982; Anderson et al., 2007; Pérez-Crespo, 2011). 
A pesar de ello, se continuó explorando los afloramientos fosilíferos del sur de México, en los estados de Puebla, Guerrero y Oaxaca (ver figura 4). Esta iniciativa de proyecto a largo plazo ha permitido generar y demostrar un cambio de paradigma paleobotánico de la región.

El nuevo enfoque paleobotánico es sustentado por varios estudios. Primero, se sugieren condiciones climáticas heterogéneas, es decir, que en las localidades de estudio y a través del Jurásico Inferior al Jurásico Medio (ver figura 5) existieron microclimas que se caracterizan y distinguen por presentar condiciones variables: desde temporadas con estrés hídrico (falta de agua) hasta aquellos con áreas de abundante humedad y pantanos (Ortiz-Martínez et al., 2013).

Dicha propuesta paleoclimática se fundamenta en análisis geológicos y del área foliar (tamaño de las hojas) de los fósiles de gimnospermas de la región. En general, los estudios paleoclimáticos se basan en plantas, ya que son uno de los mejores indicadores del clima, según el tamaño o morfología de la hoja. Esto se debe a que las hojas están en interacción directa con la atmósfera y su morfología se define en función de las condiciones climáticas (Pire y Valenzuela, 1995; Ortiz-Martínez et al., 2013).

Por otro lado, la asociación de la flora es otro elemento del nuevo enfoque paleobotánico. A finales del siglo xx, el listado paleoflorístico se constituía por quince especies de Bennettitales, dos posibles Coniferales (hoy conocidos como Pinales), seis de helechos y tres incertae sedis [latín que quiere decir en posición incierta; significa que la asignación a niveles superiores a la clasificación, en este caso especie, es dudosa (Lanteri et al., 2006)]. En total este listado estuvo compuesto por 26 especies (Person y Delevoryas, 1982; Silva-Pineda, 1984; ver tabla 1). Sin embargo, esta información se modificó recientemente, primero, con el descubrimiento de hojas de Ginkgoales y Czekanowskiales (Velasco-de León et al., 2014; Lozano-Carmona y Velasco-de León, 2014; 2015, ver figura 6a-c) y posteriormente con el hallazgo de troncos de coníferas de la familia Araucariaceae (Ortega-Chavez, et al., 2017). Además, se complementa el listado con los primeros hallazgos de esporas de helechos de la familia Matoniaceae (Martínez-Martínez, 2016; ver figura 6d). Esta información incrementa e instaura la riqueza paleoflorística de la Mixteca en el entorno paleobotánico internacional como una región sobresaliente. Son dos las localidades que sobresalen por su riqueza fosilífera y avances en su estudio, la primera corresponde al Jurásico Inferior en la comunidad de Rosario Nuevo y la segunda del Jurásico Medio en el Distrito de Tlaxiaco, ambas en la región Mixteca oaxaqueña.

\section{El bosque petri icado de Rosario Nuevo}

En el noroeste de Oaxaca se ubica Rosario Nuevo enclavado en la Sierra Madre del Sur. En esta zona hay afloramientos del Jurásico Inferior con presencia 
de fósiles de plantas. Las pruebas realizadas para corroborar la edad son fechamientos radiométricos de zircones detríticos. Destacan los numerosos troncos petrificados (permineralizados) que han sido descubiertos en patios y en calles de la población (ver figura 7a-b), uno de estos troncos alcanza 8 metros de longitud (ver figura 7c). Este ejemplar pertenece a la familia Araucariaceae, coníferas que actualmente se distribuyen en el hemisferio sur (Ortega-Chavez et al., 2017; Zepeda-Martínez et al., 2018). Otros fósiles encontrados son abundantes hojas y órganos reproductivos de Bennettitales (ver figura 8a-c) y escasos Filicales (helechos) y Cycadales (Ortega-Chavez et al., 2017, ver figura 8). Por lo tanto, en esta parte de la Mixteca, la vegetación fue un bosque de coníferas intercalado por un sotobosque compuesto por Bennettitales y helechos; estas plantas formaban un paisaje muy diferente a la selva baja caducifolia que actualmente se encuentra en el lugar.

\section{El jardín Jurásico de Tlaxiaco}

En el noroeste de Oaxaca se han descubierto y estudiado tres localidades con fósiles de plantas en áreas adyacentes a Tlaxiaco. Éstas son Río Ñumí, Cañada Alejandro y Mixtepec. Hasta el momento destaca por su riqueza Río Ñumí (RÑ, ver figura 4), la cual presenta uno de los primeros registros de Ginkgoales y Czekanowskiales y un listado de 34 especies. La flora dominante son las Bennettitales y helechos, presentándose en impresiones de hojas, órganos reproductivos y frondas, respectivamente (Velasco-de León et al., 2013, 2014; Lozano-Carmona y Velasco-de León, 2014, 2015, 2016, ver figura 9).

De esta localidad fue propuesta una reconstrucción hipotética del ambiente, que correspondería a una planicie deltaica con pantanos. Fue realizada con base en el análisis de características sedimentarias y relaciones estratigráficas (Corro y Ruiz, 2011). Al interpretarse la distribución y el hábito de la flora en dicho ambiente se infiere que es posible que tuviera la apariencia de un matorral, es decir, una vegetación baja entre las zonas pantanosas y los canales del delta. Mientras que, hacia la periferia de la cuenca las Ginkgoales y Czekanowskiales se formarían pequeños manchones de bosque (Lozano-Carmona, 2012). Por lo tanto, en Río Ñumí durante el Jurásico Medio se presentó un paisaje muy diferente al bosque de pino-encino que hoy existe.

Si bien son numerosos los trabajos de la flora jurásica de la Mixteca que aportaron nuevas especies y listados florísticos, todos hacen referencia al trabajo pionero realizado por George Reber Wieland a principios del siglo xx. Dicho trabajo cumple 106 años de su publicación y la intervención de Wieland en México introdujo un hito en la paleobotánica norteamericana. 


\section{Un poco de historia: La paleobotánica de la Mixteca oaxaqueña}

George Reber Wieland (1865-1953) fue Paleontólogo de la Universidad de Yale, Estados Unidos y estudió fundamentalmente Cycadas mesozoicas. Uno de sus principales aportes fue que Yale lograra una colección de 1,000 ejemplares de fósiles de Cycadas (Yale Peabody Museum of Natural History, 2017).

G. R. Wieland fue contactado por el Sr. Ing. José Guadalupe Aguilera en la celebración del Centenario de la Sociedad Geológica de Londres en 1907. En esta reunión Aguilera le expone a Wieland del registro de flora mesozoica del noroeste de Oaxaca, que no había sido estudiada a fondo. Wieland llega a México dos años después y comienza una serie de expediciones en El Consuelo y Tlaxiaco, Oaxaca. En su publicación La flora Liásica de la Mixteca Alta, resaltó la abundancia y excelente conservación de los fósiles de plantas. Además, enfatizó varias observaciones referentes a la distribución y origen de la flora de la Mixteca, comparándola con lo que se sabía en el ámbito internacional. En general, Wieland consideró que esta flora tenía alto potencial de estudio, tanto taxonómico como biogeográfico (Wieland, 1914). Sin embargo, es posible que la Revolución mexicana (1910-1917) impidiera su retorno para continuar con sus estudios, además de que se enfocó en trabajar en el Fossil Cycad National Monument en Dakota del Sur.

Posterior al trabajo de Wieland, entre 1960 y 1990, la Dra. Alicia Silva Pineda y el Dr. Theodore Delevoryas, entre otros paleobotánicos, retoman dichas localidades de estudio. Durante estas décadas de trabajo la paleobotánica de la Mixteca es enriquecida con registros de nuevas especies y listados paleoflorísticos (Delevoryas y Gould, 1971; Delevoryas y Person, 1975; Silva-Pineda, 1984). En la actualidad se continúa su estudio.

\section{Conclusiones}

Podemos constatar que, a más de un siglo del trabajo de Wieland en la Mixteca, aún se realizan hallazgos de nuevos taxones, principalmente gimnospermas, los cuales han permitido enriquecer los listados previos y plantear nuevas propuestas paleoclimáticas. Esto permite concluir que la riqueza paleoflorística del Jurásico de la Mixteca es un patrimonio que podrá ser estudiado por mucho tiempo, que será la base para la formación de paleobotánicos mexicanos y puede ser comparable con localidades internacionales como lo estimó George Reber Wieland. Además, estos estudios nos permiten tener una ilustración clara de los cambios de vegetación y climáticos que se han presentado a lo largo del tiempo geológico en el territorio nacional. 
"Flora jurásica de la Mixteca oaxaqueña: patrimonio paleobotánico de México"

Diego Enrique Lozano-Carmona y María Patricia Velasco de León

Figura 1. Gimnospermas, plantas sin flor y semilla desnuda. Estas plantas dominaron el paisaje durante el Jurásico. En la actualidad podemos encontrarlas aún en varias regiones del mundo.

Figura 2. Ejemplares fosilizados de a) hojas, b) tallos, c) troncos petrificados y d) estructuras reproductoras que se han encontrado en la región Mixteca. Autor: Diego E. Lozano Carmona.

\section{Galería}
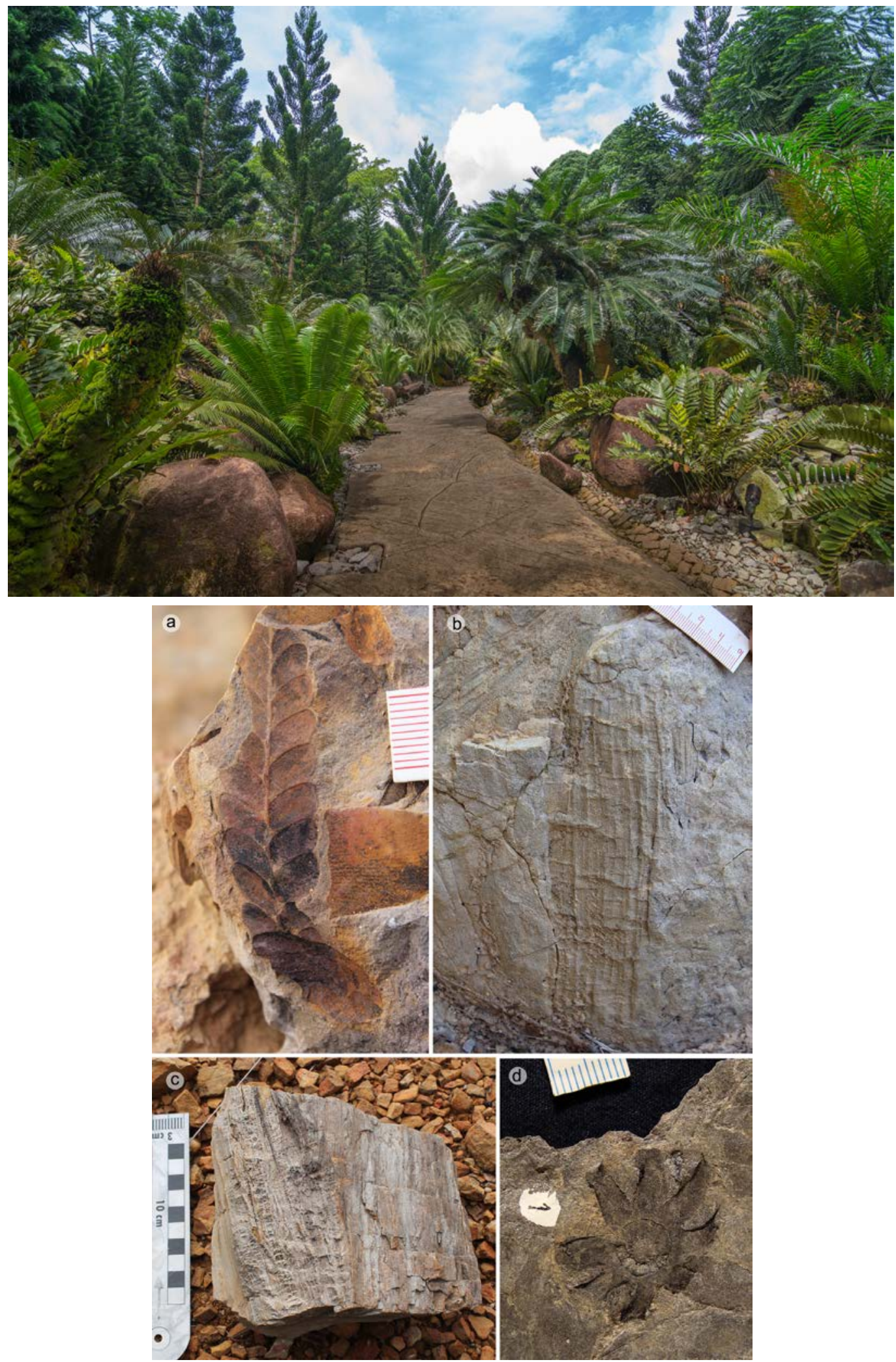
Figura 3. Algunas especies de plantas del Jurásico de la región Mixteca: a) Brachyphyllum sp., b) Taeniopteris orovillesnsis, c) Zamites lucerensis, d) Sagenopteris nilssoniana, e) Williamsonia sp. La escala es de $1 \mathrm{~cm}$ en todas las imágenes. Autor: Diego E. Lozano Carmona.

Figura 4. Mapa compuesto. a) El sur de México, el polígono engloba a los afloramientos fosilíferos del Jurásico, la región Mixteca oaxaqueña delineada y las localidades Rosario Nuevo (RN) y Río Ñumí (RÑ). Los recuadros RN) y RÑ) son secciones modificadas de las cartas geológico-mineras donde se observa la ubicación de las localidades de estudio, vías de acceso y zonas habitadas. Autor: Diego E. Lozano Carmona.
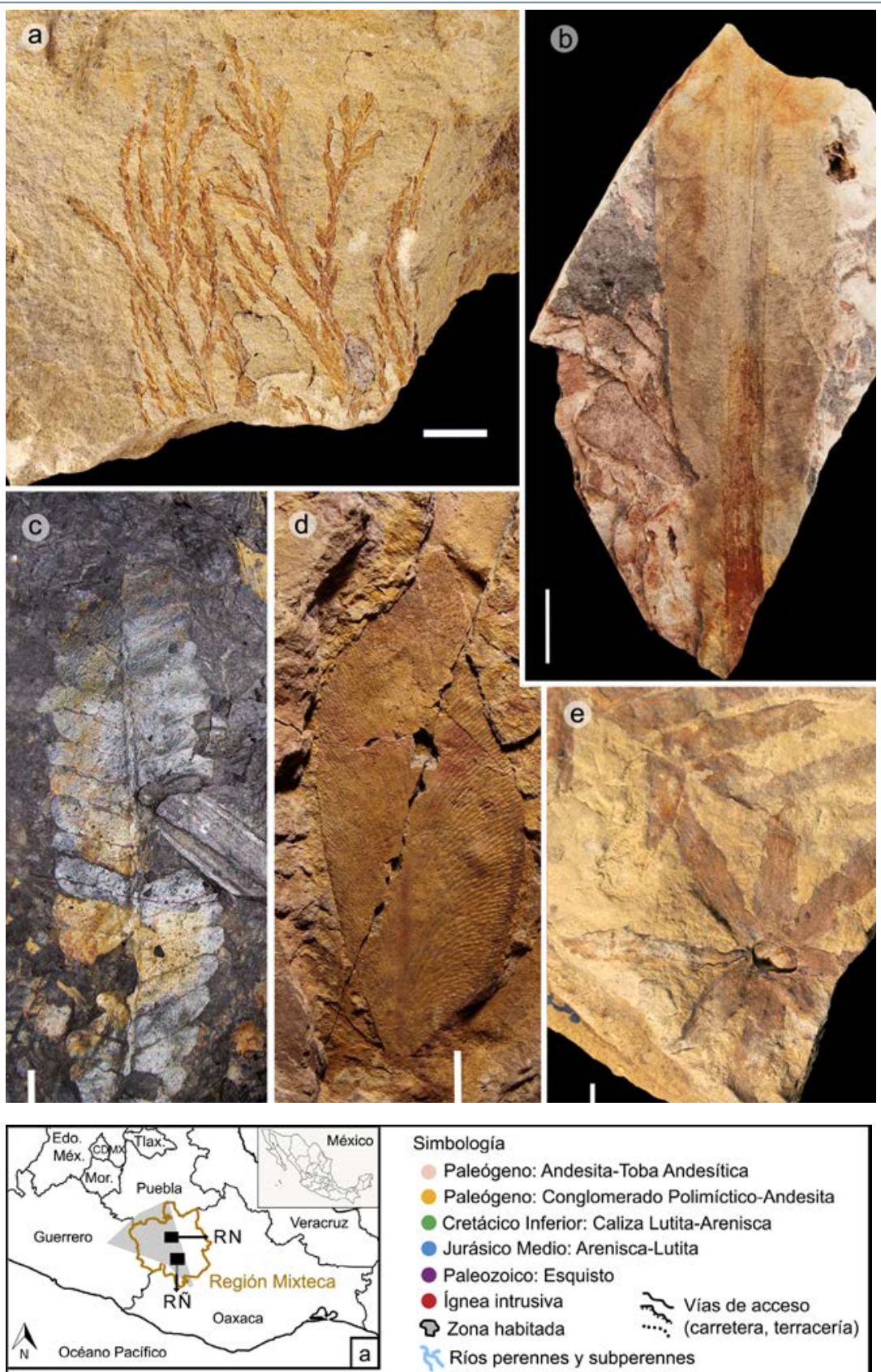

Simbología

(1) Paleógeno: Andesita-Toba Andesitica

- Paleógeno: Conglomerado Polimíctico-Andesita

- Cretácico Inferior: Caliza Lutita-Arenisca

- Jurásico Medio: Arenisca-Lutita

- Paleozoico: Esquisto

- Ignea intrusiva

? Zona habitada

Vias de acceso

₹- Ríos perennes y subperennes

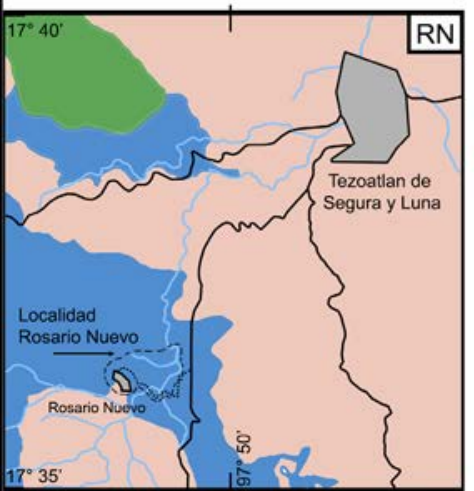


Figura 5. Sección modificada de la tabla cronoestratigráfica internacional. Se puede observar el orden cronoestratigráfico del Jurásico.

Figura 6. Imágenes de impresiones de hojas de Ginkgoales y Czekanowskiales, y una espora de helechos de la familia Matoniaceae. En a) se observa una hoja del género

Eretmophyllum, las flechas blancas señalan la forma del ejemplar. En b) se muestran lacinias (hojas filamentosas) del género Czekanowskia, la flecha blanca indica la base del racimo. En c) se observan segmentos de una hoja de Ginkgoites, las

flechas blancas indican un segmento. En d) se puede ver una espora trilete de la familia

Matoniaceae. Autores: (a-c)

Diego E. Lozano Carmona y (d) Pedro C. Martínez.
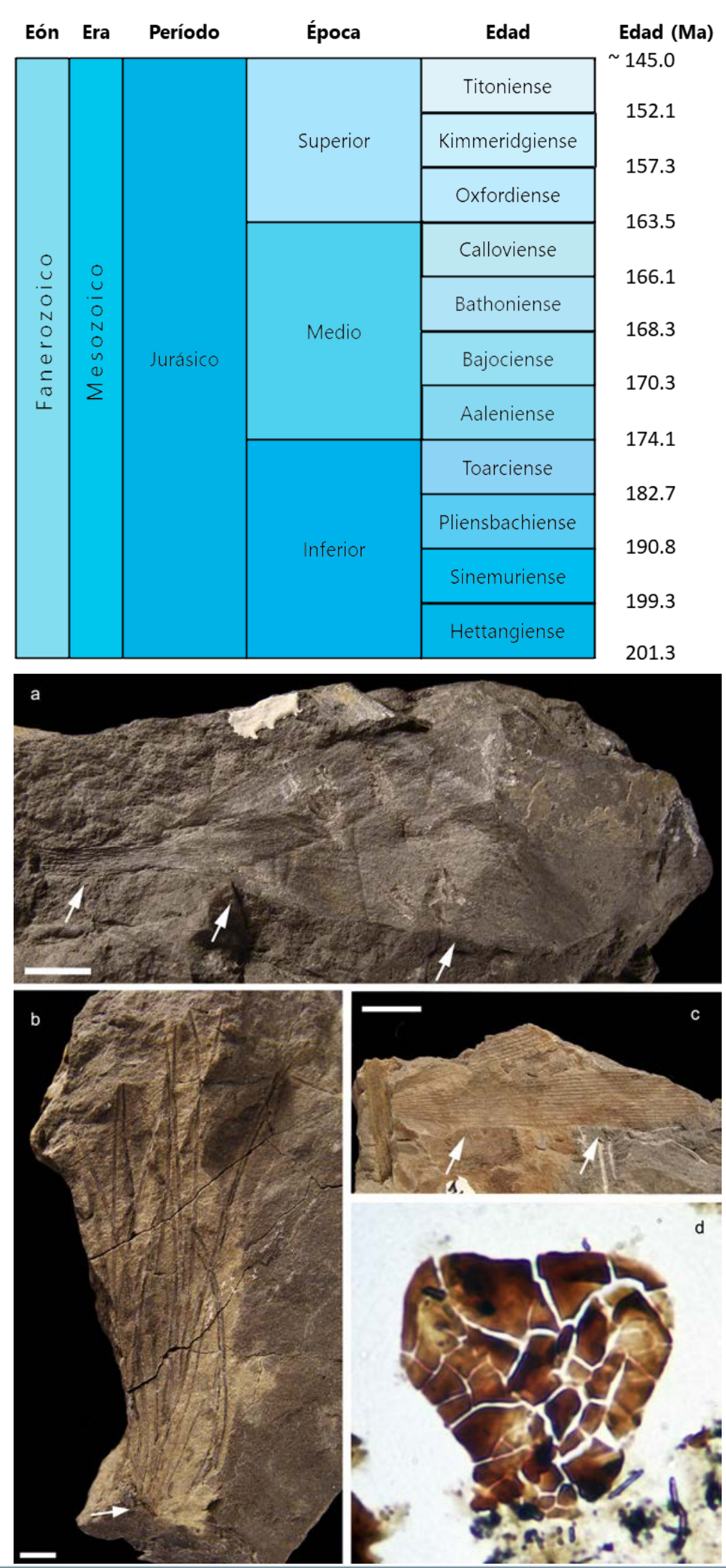
"Flora jurásica de la Mixteca oaxaqueña: patrimonio paleobotánico de México"

Diego Enrique Lozano-Carmona y María Patricia Velasco de León Vol. 21, Núm. 3, mayo-junio 2020 Revista Digital Universitaria

Figura 7. Troncos petrificados de la localidad Rosario Nuevo, Oaxaca. En a) y b) se pueden observar ejemplares de dos metros de longitud. En a) el tronco está expuesto, con notable erosión y fragmentado, la línea blanca indica el contorno inferior. En b) el tronco está descubierto en las veredas del poblado, parcialmente desenterrado. En c) se muestra el ejemplar de la familia Araucariaceae de ocho metros de longitud. Autor: Diego E. Lozano Carmona.
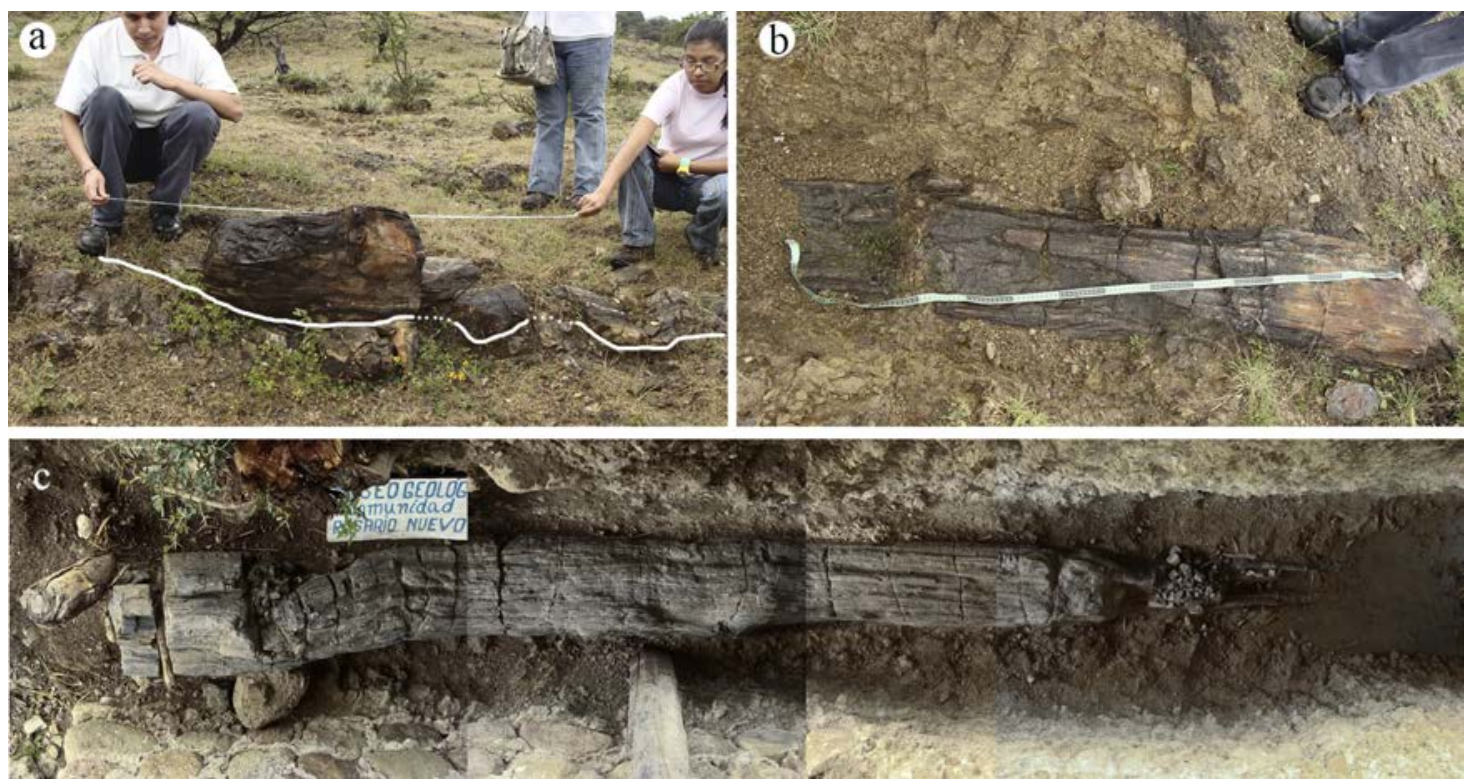

Figura 8. Fósiles de plantas de Rosario Nuevo, Oaxaca. En a) se observa una hoja de Otozamites pinnaticompuesta (hoja compuesta por varios foliolos unidos a un raquis). En b) y c) se muestran dos ejemplares de estructuras reproductivas (conos) del género Williamsonia. En c) se observan frondas de helechos del género Phlebopteris. Autor: Diego E. Lozano Carmona.
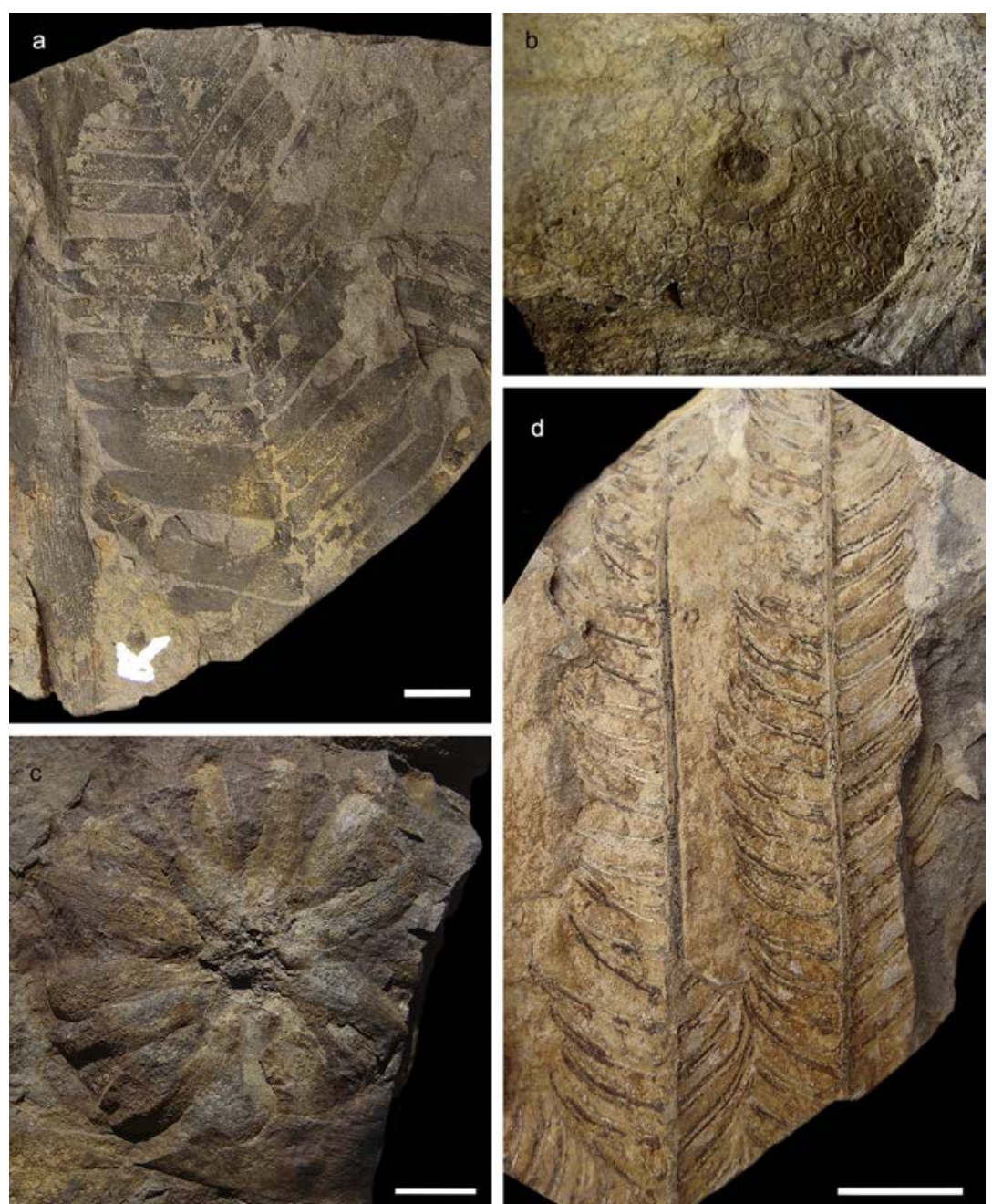
"Flora jurásica de la Mixteca oaxaqueña: patrimonio paleobotánico de México" Diego Enrique Lozano-Carmona y María Patricia Velasco de León Vol. 21, Núm. 3, mayo-junio 2020 Revista Digital Universitaria

Figura 9. Imágenes de los fósiles de plantas de la localidad Río Ñumí, Oaxaca. En a) y b) se observan hojas pinnaticompuestas de Bennettitales de los géneros Otozamites y Ptilophyllum,

respectivamente. En c) se conserva una impresión de un cono del género Williamsonia. Autor: Diego E. Lozano Carmona.
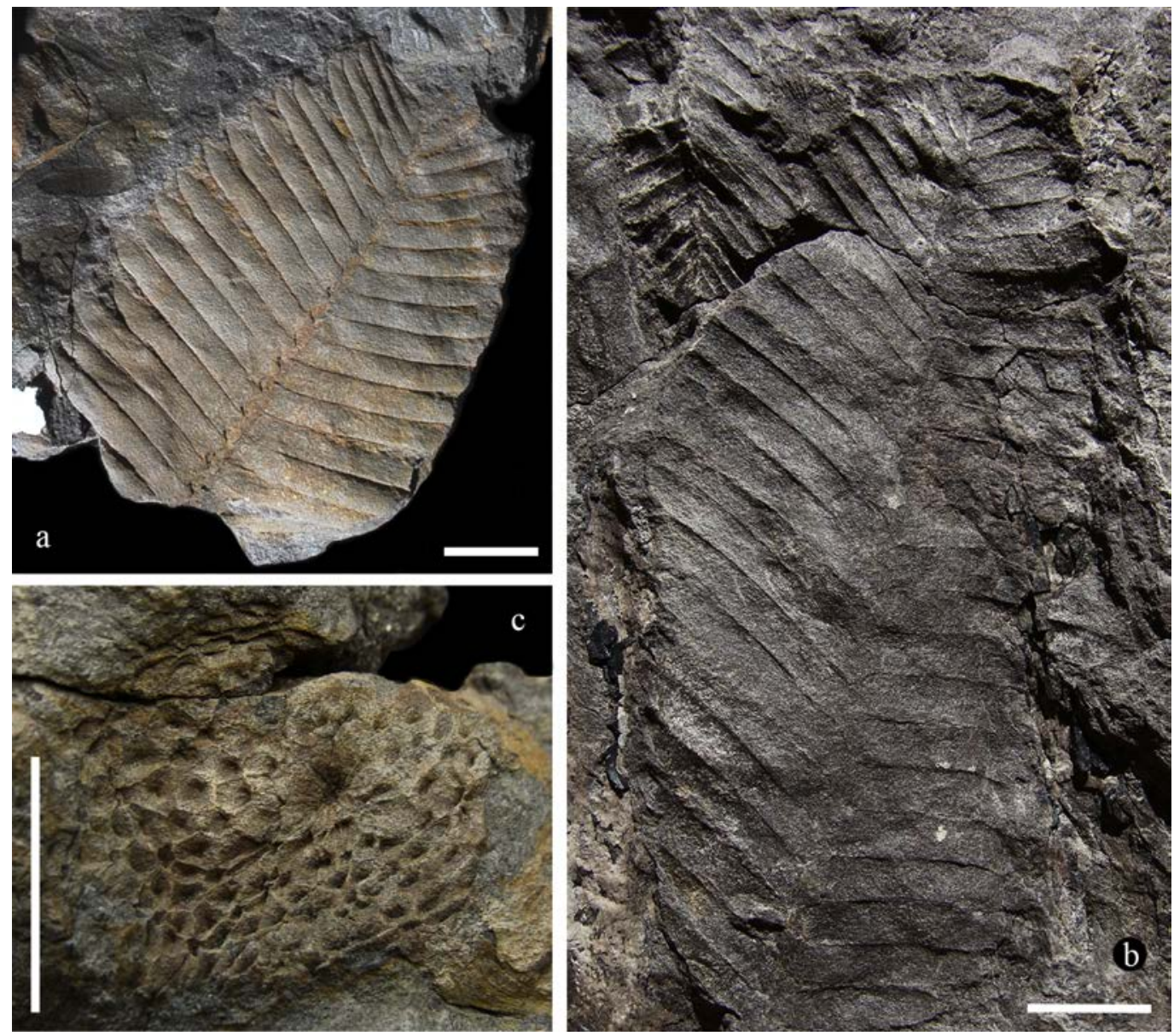

\section{Referencias}

* Anderson,J. M., Anderson, H. M., y Cleal, C.J. (2007). Briefhistory of the gymnosperms: classification, biodiversity, phytogeography and ecology. Strelitzia 20.

- Corro, M. G. y Ruiz, F. J. (2011). Análisis estratigráfico de las secuencias jurásicas del área de Tlaxiaco, Oaxaca [tesis de licenciatura, Universidad Nacional Autónoma de México, Facultad de Ingeniería]. http://132.248.9.195/ptb2011/mayo/0668902/Index.html.

- Delevoryas, T. y Gould, R. E. (1971). An Unusual Fossil Fructification from the Jurassic of Oaxaca, Mexico. American Journal of Botany, 58(7), 616-620. https:// www.jstor.org/stable/2441005.

Delevoryas, T. y Person, C. P. (1975). Mexig/ossa varia gen. et sp. nov., a new genus of glossopteroid leaves from the Jurassic of Oaxaca, México. Palaeontobraphica, Abt. B., 154, 114-120.

- Diéguez C. (2003). Flora y vegetación durante el Jurásico y Cretácico. Monografía del Jardín Botánica, Córdoba. 11, 53-62. https://www.uco.es/ucopress/ojs/index. php/rejabot/article/view/4086. 
"Flora jurásica de la Mixteca oaxaqueña: patrimonio paleobotánico de México"

Diego Enrique Lozano-Carmona y María Patricia Velasco de León

* Lanteri, A. A., Cigliano, M. M. y Fernández, M. S. (2006). Cladística, Clasificación, y decisiones taxonómicas. En Lanteri, A. A. y Cigliano, M. M. (Eds.), Sistemática Biológica: Fundamentos teóricos y ejercitaciones (pp. 175-188). Editorial de la Universidad de La Plata.

* Lozano-Carmona, D. E. y Velasco-de León, M. P. (2014). Primer registro de Czekanowskia Heer, 1876 (Gymnospermae, Czekanowskiales), del Jurásico de México. Memorias del ॥ Simposio de Paleontología en el sureste de México, Universidad del Mar, Campus Puerto Escondido, Oaxaca. http://dx.doi.org/10.13140/ $\underline{R G .2 .2 .11318 .60484 .}$

* Lozano-Carmona, D. E. y Velasco-de León, M. P. (2015). Primer registro de Eretmophyllum (Ginkgoales), en el Jurásico de México. Ameghiniana, 52(4), 34-35. http//www.bioone.org/doi/full/10.5710/AMGH.v52i4.2.

* Lozano-Carmona, D. E., y Velasco-de León, M. P., (2016). Jurassic flora in Southeast Mexico: importance and prospects of recent findings in the Mixteco Terrane. Paleontología Mexicana, 5(2), 87-101. http://www.ojsigl.unam.mx/index.php/ Paleontologia/article/view/554.

- Lozano-Carmona, D. E., Guerrero-Arévalo, I. D. y Velasco-de León, M. P. (2016). Un paleontólogo en la Mixteca Alta; una perspectiva a más de 100 años de los trabajos de G. R. Wieland (1909-1914). Memorias del ॥I Simposio de Paleontología en el sureste de México, Puebla de los Ángeles.

* Martínez-Martínez, P. C. (2016). Pínnulas de Phlebopteris sp. y nuevos registros de esporomorfos de la localidad Cerro Prieto del Jurásico de Oaxaca. III Simposio de Paleontología en el sureste de México, Puebla de los Ángeles.

* Ortega-Chavez, E., Velasco de León, M. P. y Rentería Jiménez, J. (2017). Agathoxylon sp. Del Jurásico Inferior, Rosario Nuevo, Oaxaca, México. Paleontología Mexicana, 6(2), 73-77. http://www.ojs-igl.unam.mx/index.php/Paleontologia/article/view/581.

- Ortiz-Martínez, E. L., Velasco de León, M. P., Salgado-Ugarte, I. H. y Silva-Pineda, A. (2013). Clasificación del área foliar de las gimnospermas fósiles de la zona norte de Oaxaca, México. Revista Mexicana de Ciencias Geológicas, 30(1), 150-158. http://www. scielo.org. $\mathrm{mx} /$ scielo.php? script=sci arttext\&pid=S1026-87742013000100010.

* Pérez-Crespo, V. A. (2011). Estado actual del conocimiento de las plantas fósiles de Oaxaca, México. Naturaleza y Desarrol/o, 9(1), 47-59. https://www.uv.mx/personal/ tcarmona/files/2010/08/Perez-2001.pdf.

* Person, C. P. y Delevoryas, T. (1982). The Middle Jurassic Flora of Oaxaca Mexico. Palaentographica, Abt. B., 180, 82-119.

* Pire R. y Valenzuela, I. (1995). Estimación del área foliar en Vitis vinífera L. French Colombard' a partir de mediciones lineales en las hojas. Agronomía tropical, 45(1), 143-154.

* Silva-Pineda, A. (1984). Revisión taxonómica y tipificación de las plantas jurásicas colectadas y estudiadas por Wieland (1914) en la región de El Consuelo, Oaxaca. Paleontología Mexicana, 49, 1-103. http://www.ojs-igl.unam.mx/index.php/ Paleontologia/article/view/74. 
* Velasco-de León, M. P., Ortiz, M. E., Silva-Pineda, A. y Lozano-Carmona D. E. (2013). Distribución y Ambientes de las Gimnospermas fósiles del Terreno Mixteco. Paleontología Mexicana, 2(1), 122-143. http://www.ojs-igl.unam.mx/index.php/ Paleontologia/article/view/163.

* Velasco-de León, M. P., Lozano-Carmona, D. E., Flores, B. M. A., Martínez, P. O. D. y Silva-Pineda, A. (2014). Two new species of Ginkgoales from the Middle Jurassic of México. Historical Biology: An International Journal of Paleobiology, 27(3-4), 366-373. https://doi.org/10.1080/08912963.2013.874423.

* Wieland, G. R. (1914). La flora liásica de la Mixteca Alta. Boletín del Instituto Geológico de México, 31, 1-165.

- Yale Peabody Museum of Natural History. (2017). George Reber Wieland. http:// peabody.yale.edu/collections/archives/biography/george-reber-wieland.

* Zepeda-Martínez, M., Martini M. y Solari, L. (2018). A major provenance change in sandstones from the Tezoatlán basin, southern Mexico, controlled by Jurassic, sinistral normal motion along the Salado River fault: Implications for the reconstruction of Pangea. Journal of South American Earth Sciences, 86, 447-460. https://doi.org/10.1016/j.jsames.2018.07.008.

Zhou, Z-Y. (2009). An overview of fossil Ginkgoales. Palaeoworld, 18, 1-22. https:// doi.org/10.1016/j.palwor.2009.01.001.

\section{Sitios de interés}

- Earth Viewer. BioInteractiva.

- The Jurassic Foundation.

- Jurassic Period Geochronology de la Encyclopedia Britannica

- Sociedad Mexicana de Paleontología

\section{Cómo citar este artículo}

* Lozano-Carmona, Diego E. y Velasco de León, María P. (2020). Flora jurásica de la Mixteca oaxaqueña: patrimonio paleobotánico de México. Revista Digital Universitaria (RDU) Vol. 21, núm. 3 mayo-junio. Dol: http:// doi.org/10.22201/codeic.16076079e.2020.v21n3.a11.

Recepción: 06/05/2018. Aceptación: 23/09/2019. 